\title{
Family Structure Trajectories and Early Child Health in the UK: Pathways to Health
}

Lidia Panico ${ }^{1}$ (1), Melanie Bartley (2), Yvonne Kelly (2), Anne McMunn (2), Amanda Sacker (2)

(1) Institut National d'Etudes Démographiques (INED), 133 Boulevard Davout, 75980 Paris cedex 20, France.

(2) ESRC International Centre for Lifecourse Studies, Dept Epidemiology and Public Health, University College London, 1-19 Torrington Place, London, WC1E 6BT, United Kingdom.

Keywords: Family structure; Family instability; Early child health; Asthma; Obesity; Accidents; Millennium Cohort Study

${ }^{1}$ Corresponding Author : Lidia Panico, INED, 133 Boulevard Davout, 75980 Paris cedex 20, France.

Lidia.panico@ined.fr, +33(0)156062053. 


\section{Abstract}

A large body of literature has shown marked differences in the average levels of resources and child well-being across different family structures. Studies have examined cognitive, educational and behavioural outcomes; less is known about differentials in physical health, and about dynamics in early childhood.

Furthermore, up to the present time, less emphasis has been placed on describing the underlying mechanisms relating childhood experience of family structure to health. In this paper, we hypothesize that socio-economic characteristics and family structure trajectories will affect everyday, more proximal processes (material, behavioral and family stress pathways) directly experienced by the child, which will in turn affect child health.

Using the UK Millennium Cohort Study, a nationally representative cohort of over 19,000 children born in 2001 and living in the UK shortly thereafter, we employ Graphical Chain Models to map the processes linking family structure trajectories to three physical health outcomes at age 5: overweight/obesity, respiratory health, and accidental injury. We construct family trajectories to highlight two components: status (distinguishing between married, cohabiting and single parents), and (in)stability.

We show that both status, the (in)stability of that status, and their interplay, are important components of family structure trajectories which correlate to children's early physical health. Analyses highlight the relative importance of distinct pathways across different health outcomes. As well as some outcome-specific paths, we find that "family stress" variables appeared to underscore the relationship between family structure and child physical health, pointing to the importance of such variables in understanding how family structure relates to early child health. 


\section{Introduction}

Families provide a wide range of social, economic and emotional resources that influence child health and development; the average level of these resources varies across different family types. An extensive literature has shown that children growing with two continuously married parents do better on average on several cognitive, emotional and developmental outcomes, in childhood and adulthood [1-5]. We know less about physical health, especially in the early years, a key stage for understanding lifelong health trajectories.

Research on family structure and child outcomes has concentrated on describing differentials, or testing whether associations are causal [6]. Less emphasis has been placed on describing potential underlying proximate processes that might link family structures to child well-being. However, describing plausible mechanisms through which effects could work is important for scholarship, and is useful for public policy purposes. To describe potential underlying processes, considering family structure from a longitudinal and nuanced perspective is important. First, the resources available to different family types and the form and function of the family differ within the broad groups often used: one versus two-parent households, married versus unmarried parents. Furthermore, family structure is not static and children can experience changes, even from early childhood. These trajectories are linked to both available household resources and to markers of child and parental well-being [7, 8]. Thus, detailed and dynamic measures of family structure can help unpack the relationships between family structure and outcomes for children.

This work therefore explores whether family structure trajectories are correlated to three domains of early physical health: respiratory health, overweight/obesity, and accidental injuries, in a 
nationally representative sample of children residing in the UK. We construct family trajectories to highlight two components of such trajectories: status (distinguishing between married, cohabiting and single parents), and (in)stability (remaining within the same status or moving from one status to another). While remaining descriptive, the focus of our analyses is describing potential proximate processes that could link contextual factors such as family structure trajectories to children's physical health. Different spheres of health are considered to better understand these processes, as we hypothesised that different health outcomes would be associated with different processes. The focus on early childhood allows describing how these relationships develop during a crucial developmental window, and when children spend more time within the family sphere, allowing better capturing family processes.

\subsection{How family structure may affect early childhood physical health}

While less is known about the link between family structure and child physical health, particularly in the early years, the available studies present results consistent with the wider literature on family structure and child development. This broader literature has shown that experiences of parental divorce and unmarried parenthood are associated with poorer emotional, psychosocial and educational outcomes, especially for teenagers, while children living in intact two-parent families tend to report the best outcomes [9-11]. For example, work on the Millennium Cohort Study by Kiernan and Mensah (2011) identified differences across a number of family trajectories in children's emotional well-being at 5 years of age [12]. They showed that children who had experienced different family trajectories varied in terms of emotional and behavioral problems, suggesting that family instability and change appears to be important in explaining differences in early childhood behavioural problems. The wider impact of family structure on child well-being 
has been linked to increasingly polarized experiences of union formation and dissolution across socio-economic groups [13-15].

These negative impacts appears to persist into adulthood, although effects are relatively modest, probably because children who experience parental divorce are not a homogenous group $[1,16]$. However, negative effects have persisted over time, even as divorce has become more common and less stigmatized [16]. In particular, the timing of family transitions might be a source of heterogeneity: transitions occurring in early childhood appeared to be especially detrimental to subsequent child development [17].

Turning to studies exploring specifically the association between family structure and child physical health, the few studies available appear to confirm the trends for other child outcomes. They highlight that family instability [18], marital status [19], and their intersection [20], were related to children's physical health outcomes such as asthma, general health status and overweight. However, much of this work employs data from the Fragile Family study, which is representative of particular time periods and sub-groups [21], and relate to a national setting, the USA, with certain socio-demographic characteristics, notably a high proportion of births to single mothers, and high family instability. In fact, the broader evidence for theories around the impact of family structure on child outcomes is primarily from the United States, where economic inequality has been very marked [22]. Different national contexts, such as Australia [23], or Sweden [24], are also reporting similar associations between family structure (and in particular, partnered vs unpartnered households) and child well-being. However, the association between socio-economic background and family structure trajectories events (such divorce or repartnering) appears to differ across countries and over time [25]. Thus, while the relationship between family structure and 
child well-being seems to be universal, it is not clear whether the mechanisms underlying these correlations can be generalized across countries.

Work specific to the UK is more sparse but expanding. Nationally-representative data from the Millennium Cohort Study has found significant differences according to family structure in wellknown predictors of child health such as breastfeeding and parental smoking $[8,26]$. These results are reflected in cross-sectional work showing associations between lone parenthood and child general health, long-standing illness, injury, overweight, and asthma [27], and longitudinal analyses showing that living with a lone mother increased the risks of obesity by age 7, compared to continuously living with two biological parents [28]. The emphasis on lone parenthood did not allow distinguishing between married and cohabiting parents, and the focus on causation meant that less attention could be paid to the mechanisms underlying the relationships described.

Hypothesizes that could explain health differentials by family structure can be summarised in two: mechanisms we consider to be largely "upstream" from family structure, notably socio-economic status; and "downstream" or proximate mechanisms, such as parental health behaviours. Starting with "upstream" processes, studies suggest that the relationship between family structure and child well-being may be intricately intertwined and driven by different socio-economic characteristics $[1,27,29-31]$. For example, in the UK, single mothers are more likely to be unemployed and to reside in social housing [32] and to be persistently in poverty [8]. Furthermore, parental separation often entails increases in childhood poverty and deprivation, particularly for more disadvantaged groups [33]. 
However, socio-economic characteristics and family structure are contextual factors and do not, per se, cause poor health. A number of intertwined pathways have been put forward to explain the "social to biological" transition [34], although this literature has not considered family structure as a key social stratification variable. Classic economic explanations posit that socio-economic differentials produce differences in parents' abilities to invest in their children's human capital $[35,36]$. For our analyses, this material pathway could suggest a role of, for example, housing quality or adequate nutrition. In epidemiology, a behavioural/lifestyle path has been extensively tested to explain socio-economic inequalities in health (see Bartley [37] for a review). In the UK, socio-economic position is, for example, linked to smoking, diet, and physical activity [38]. A less explored pathway, from the psychological literature, is family stress. Family stress models hypothesize that (financial) stressors affect children through exposure to poor parental mental health, parental conflict and parenting skills $[39,40]$, which are strongly correlated to child wellbeing [12, 41, 42]. While Conger's original model explored adolescent well-being, similar models have since been successfully adapted for young children [12, 31, 43]. While the family stress model has been mostly applied to cognitive and developmental outcomes and less to child health, it is documented that stress is linked to physical health [44], including to child health outcomes such as asthma [45]; and that stress may both mediate between socio-economic difficulties and child health [46] and interact with socio-economic status to impact child health. For example, children from socially or economically disadvantaged households had a greater cardiovascular reactivity to stress than children from higher status households [47]. In fact, recent research has shown how environmental experiences, including poverty and the family environment, affect the underlying neurological, biological and physiological processes governing child development (often referred to how life exposures "get under the skin"). Children have been shown to have a direct impact of 
stress on their health, similarly to adults, through a physiological health response $[48,49]$. In this response, the activation of the hypothalamic-pituitary-adrenal (HPA) axis leads to the secretion of glucocorticoids from the adrenal glands. A chronic secretion of glucocorticoids can damage physical health due to allostatic load processes, i.e. the wear and tear of various physiological systems (metabolic, immune, etc.) related to HPA activation [50].

Disentangling material, behavioural, and stress proximal pathways, is complicated, as these are likely to co-occur and be interdependent (for example, poor parental mental health might impact health behaviours; and low incomes might increase family stress). One way to unpack the role of different pathways is to investigate different health outcomes with different underlying biological mechanisms. In this paper, we look at three different spheres of child health, allowing us to put forward different expected underlying mechanisms. As detailed further in the next section, hypotheses can be made about the relative importance of these three sets of pathways (and their individual components) according to the outcome considered. Further linking these pathways to different family trajectories can highlight whether some mechanisms are specific to different family set-ups, or whether they are universal across non-traditional family structure trajectories.

\section{Conceptual model}

In this paper, we hypothesize that socio-economic characteristics and family structure trajectories will affect every-day, more proximal processes (material, behavioural and family stress pathways) directly experienced by the child, which will in turn affect child health (Figure 1). 
The model focuses on a description of the potential mechanisms underlying the correlation between family structure and child health, although it does not depict causal associations. The model is organized into four "levels" allowing a conceptual differentiation between distal and proximal variables [51]. Variables are grouped into conceptual blocks describing common constructs. Variables to be included in these conceptual blocks vary according to the health outcomes considered, and reflect the mechanisms put forward in the literature. Respiratory illnesses such as asthma imply chronic inflammation of the airways. Inflammatory processes regulated by immune and neural phenomena provide plausible biological pathways through which psychosocial stress could influence asthma expression [52]. Allergy plays an increasingly important role past the infant stage. We therefore expect exposure to allergens as proxied by housing quality, breastfeeding initiation, and variables relating to family stress to be highlighted for this health outcome. And at all ages, exposure to environmental pollution and passive smoking is known to have a very strong relationship with different aspects of respiratory health such as wheeze and asthma. While we are not able to explore environmental pollution, we include questions on parental smoking in these models. Finally, while evidence on early childhood remains less conclusive, a growing literature has highlighted the importance of sedentary behaviour to at least explain the increase in asthma prevalence in developed societies. We therefore hypothesise that sedentary activities such as long daily screen use might be relevant for these models.

The development of overweight and obesity is linked to growth: the infant stage is largely driven by nutrition, and later life stages by hormones. While quality of diet and sedentary patterns are clearly important, stress may also have a (direct) role as it affects secretions of growth hormones, as well as have an indirect role through parents' behaviours, including their ability to provide 
nutritious meals and opportunities for physical activity. Prenatal exposures, such as maternal smoking, may also be important through a role on foetal growth.

Finally, accidental injury in young children appears to be linked to lower levels of supervision, which could be proxied by markers of structured parenting, and a more dangerous home environment $[53,54]$. This may be driven by financial constraints and housing tenure: for example, those living in rentals may be unable to fit safety equipment [55], or afford such equipment [56].

Blocks are primarily ordered in a theoretically and conceptually driven manner, rather than a strictly temporal fashion. A more temporal ordering would have been beneficial, but difficult for several reasons. First, treating health variables in a longitudinal manner in young children would imply that the outcome has the same meaning across the ages considered. However, for example, wheeze at 9 months may be a temporary symptom due to constricted small airways, while by 5 years atopy becomes increasingly important. Therefore, the health variables are measured at the end of the observed period: at 5 years of age. The rest of the model is mostly time-ordered, with "baseline" socio-economic variables in level 1 measured at the first wave of data collection, and pathway variables measured before the health outcomes, except in a few cases (such as diet and exercise) when data was not available until age 5. To be outcome-relevant, the proximal processes (level 3) are adapted for each health outcome, described in the next section. Also included on level 3 are measures of the household's changing economic environment, allowing modelling income gains and losses over the study period. 


\section{Data and Methods}

\section{Millennium Cohort Study}

The Millennium Cohort Study (MCS) is a nationally-representative study of 18,818 children living in the UK at 9 months of age and born in 2000-1. Households were identified through the Department of Work and Pensions Child Benefit system and selected on place of residency shortly after birth. Uptake of Child Benefit is almost universal (98\%). The sample has a probability design and is clustered at the electoral ward level. The sampled wards over-represent areas with high ethnic density and/or high child poverty, and the three smaller UK countries [57].

The first three data waves are used, collected when cohort members were aged about 9 months, 3 years and 5 years. The overall response rate for wave 1 was $68 \%$. Final sample sizes were 18,818 cohort children at wave 1;15,808 at wave 2; and 15,459 at wave 3 [58]. The study mainly consisted of face-to-face interviews with the main carer, usually the mother, and some direct measurements with the children. Information about the main respondent's resident partner was collected in a separate interview with them.

\section{Measures}

\section{Family structure trajectories}

A longitudinal measure was created representing a typology of family structure trajectories from birth to age 5. These trajectories capture two key distinct elements of family structure that may 
shape child well-being: status (whether the household contains two married, two cohabiting, or a single parent), and (in)stability (whether households remain within their same status throughout the study period or move from one status to another). These trajectories are described in Table 1, and in more detail in Panico et al. (2010).

\section{Child health outcomes}

Three groups of health outcomes are examined: respiratory health, overweight, and unintentional injury, measured at 5 years old. Questions on asthma and wheezing were available as part of the interview with the main carer, using the ISAAC (International Study of Asthma and Allergies in Childhood) core questionnaire, a widely used and validated instrument (ISAAC Steering Committee, 2000). Reports of ever asthma and wheeze in the last year are examined. The cohort members' height and weight were measured by the interviewer at age 5. We use international cutoff points for overweight and obesity based on BMI and age $[59,60]$. The main carer was asked about any injuries that required contact with medical services since the last interview (between about ages 3 and 5).

\section{Socio-economic antecedents}

The first block of variables describes the household's socio-economic baseline characteristics, collected at the first wave. The income of the resident partners (including any welfare or child maintenance) was reported by the main respondent. The variable used for modelling purposes is a continuous, log-transformed measure of weekly net income. Questions to the main respondent on the number of cars and vans owned by the household measure the household's access to the resources required to own and maintain a vehicle. The highest educational qualification held by either resident partner is used as a measure of social position. The variable is classed according to 
the National Vocational Qualification (NVQ) classification. Categories for analyses are: no qualifications, overseas qualifications only, NVQ1, NVQ2, NVQ3, NVQ4, and NVQ5. Roughly, an NVQ5 is equivalent to a graduate degree; an NVQ3 to two A-levels (secondary qualifications). For simplicity, we present models with education as a linear variable. Alternative specifications using education as a categorical variable did not affect the key relationships of interest.

\section{The emotional environment of the child}

Parental mental health is assessed at 9 months through the Malaise Inventory, a self-completion scale assessing psychiatric morbidity. At age 3, psychological distress was assessed using the sixitem Kessler Psychological Distress Scale. Both scales have good reliability and validity [61, 62]. Continuous scores were used in analyses.

The Golombok-Rust Inventory of Marital State is a questionnaire designed to assess the quality of the relationship within a couple. It produces an overall score of relationship quality [63]. The reduced questionnaire was included at waves 1 and 2; we create a continuous score at each wave. A dummy for partner absence is added to include households with no co-resident partner.

The parent-child relationship is assessed through two measures. Attachment is measured at 9 months using the Condon Maternal Attachment Questionnaire, assessing tolerance and acceptance; pleasure in proximity; and parental competence [64]. At 3 years, the Pianta scale [65] assesses the parent's perception of the quality of the relationship with their child. Items were derived from the attachment Q-set [66], generating a total score reflecting an overall positive relationship. For both scales, a continuous score is used in models. To measure "structured parenting", we use questions 
at age 3 on whether rules were applied consistently, whether the child had regular bedtimes, and regular mealtimes. These questions loaded positively on one factor (factor loadings: $0.48,0.69$, 0.70 , respectively), therefore an overall continuous score was created.

\section{The physical environment}

Overcrowding was defined as having more than one individual per room, excluding bathrooms and kitchen. Living conditions were assessed by the presence of damp in the home, as reported by the main carer. To tap into the atmosphere in the home, the main respondent was asked whether they agreed with the statement "you can't hear yourself think" in their home. Answers on a fivepoint scale ranged from "strongly agree" to "strongly disagree". To describe neighbourhoods, a question asks the main respondent to describe how safe they feel in their area. Answers on a fivepoint scale range from "very safe" to "very unsafe".

\section{Health behaviours}

Exposure to tobacco was defined as whether either resident partner smokes. Maternal smoking during pregnancy was also included. Breastfeeding initiation, irrespective of duration, was included. All variables are reported by the main carer and coded as binary (yes/no). To describe dietary habits, two variables are retained: whether the child eats at regular times, and whether the child has breakfast regularly. Inactivity is measured by the number of the daily hours spent watching TV or playing videogames. These variables are measured at age 5 , reported by the main respondent. 


\section{Methods}

Graphical Chain Models were used to model longitudinal associations. These techniques are particularly suited for modelling complex sets of dependencies: they can include variables with different measurement properties; explicitly model cross-sectional and longitudinal associational chains; and lend themselves well to models where theory and temporality suggest an a priori ordering of variables and direction of associations [67]. Variables are partitioned into blocks (Figure 1); a directed edge (arrow) signifies that one block is thought to precede or cause another block. Blocks are split into levels; blocks in the first level are potential causes for blocks in the next level, and so on. The use of arrows and boxes gives substantive meaning to models, as they allow specifying explanatory, response or intermediate variables and the direction of the relationship between blocks. Due to the large number of variables tested in the model, we do not graphically depict all tested associations. While allowing a conceptual ordering of variables and the direction of associations, these models remain descriptive and do not produce causal analyses.

All analyses were carried out in Stata 14 [68] and applied appropriate weights to take account of the survey design.

Analyses are carried out in steps:

- A model is set up, based on a priori conceptual and temporal ordering.

- Correlations within blocks are estimated to establish convergent validity. This confirmed that variables constituting a block represented a coherent construct.

- Forward and backwards selection is manually applied to reduce the number of covariates in the model. We use backwards elimination of predictors that are conditionally 
independent of the health outcome. Further, an empirical assessment of which of variables might be removed from the model without loss of power was carried out. All priori theoretically important variables were not included in this selection process (for example, for block 1, parental education, maternal age, income were considered as essential to the conceptual model and were not included in the selection process, while car ownership and grandparents occupational status were: the latter was not retained at this stage but the former was). Mechanisms variables ("Level 3" variables) were initially selected based on theoretical relevance to the health outcome, and then included in the final models if empirically retained.

- Regression models are estimated for each variable in each block with all variables in the previous levels included as independent variables. The type of regression varies according to the measurement property of each dependent variable.

Our analytical sample excludes multiple births and households not present in wave 3 (age 5). Complete case analyses were rejected to avoid substantial sample size drops. A number of strategies have been deployed to ensure that the analyses and the conclusions drawn were valid. First, multiple imputation methods were used to fill-in missing data. The rate of missingness in model variables ranged between 0 to $26 \%$. All model variables are included in the imputation models, as well as auxiliary variables measuring socio-demographic characteristics, and design variables accounting for the clustered nature of the data. We impute on all variables including auxiliary variables, as suggested by the literature, as such variables provide extra information on the outcomes [69]. Multiple imputation techniques allow accounting for uncertainty about missing values by imputing several values for each missing data point, with variability due to both sampling 
error and model uncertainty [70]. We imputed 25 datasets and consolidated results from all imputations for analyses using Rubin's combination rules [71].

Sensitivity analyses were carried out by comparing complete cases models to models using imputed data. This showed no substantive differences, suggesting that the missing data mechanism could be MAR. In a further test, we used the FIML option in MPlus, which did not provide different substantive results from the multiply imputed models. Further robustness checks included running analyses excluding non-White British children, and running models separately for boys and girls. No substantive differences were found from the models presented here. 


\section{Results}

\section{Descriptive analyses}

Table 2 shows that there were significant differences in health outcomes at age 5 across family structure trajectories. In unadjusted analyses, children living with two stably married parents reported the best outcomes, while those always living with a single parent the worst. Considering our key trajectory elements (status, stability and transitions), we can make several observations. Notably, the interplay between status and stability/change was crucial: while stably living with two married parents appeared to produce the best outcomes, stability into single parenthood did not appear to be positive. Whether transitions were positive or negative depended on status before and after the transition. For example, while the transition from coupled to single parent appeared to be negative, nuancing between marriage and cohabitation pre-separation mattered: in fact, children whose married parents separated were slightly less likely to be overweight or obese at age 5 than children whose married parents did not separate, and there were no differences for recent wheeze. Looking at the opposite transition, single parents who re-partnered appeared to report better outcomes than those who did not re-partner, but these differences were not statistically significant, and they did not catch-up to the always partnered households. Therefore, the positive transition mattered, but did not do enough to counter the effects of instability. Cohabitants who married did not have significantly different outcomes from the always cohabiting group, showing that the stability of these households mattered more than their status.

\section{Graphical Chain Models}

The initial part of the graphical chain models is common across the three outcome-specific models. Table 3 shows the Relative Risk Ratios (RRR) from multinomial regression models for family 
structure trajectories (level 2) regressed on level 1 variables (baseline socio-economic markers). All family structure trajectories were significantly different from the "always married" group for each socio-economic marker considered, even as other socio-economic variables are adjusted for. Overall, all groups are younger, poorer and held fewer educational qualifications than the stably married group. An important exception are cohabitees who marry by the time their child was age 5, who do not have significantly lower incomes and had equal access to car ownership than the married group, once their younger ages and fewer educational qualifications were taken in account. Married parents who separated also do not have different baseline incomes than the "always married" group, and had similar ages.

Next, each variable in level 3 (the emotional, physical and health behaviours spheres, and the changing socio-economic environment) was regressed against on levels 1 and 2 (baseline socioeconomic markers and family structure trajectory). The coefficients from the linear regression models for these analyses are shown in Tables 3A-3E in the online supplementary materials.

Overall, more advantaged households were able to provide a more positive emotional environment for their children (Table 3A). Given these socio-economic variations, there are no significant differences in maternal mental well-being by family structure trajectory, suggesting direct links between socio-economic and maternal well-being mostly by-passing family structure. A number of groups reported higher levels of parent-child attachment at 9 months than the always married (the "always cohabiting", cohabitees who marry, cohabitees who separate, and those who experience more than one transition). In terms of parenting, few differences were significant: single parents who later cohabited were slightly more likely than the always married group to have a warm relationship with their child, while married parents who separated were less likely to report 
a warm relationship at 3 years of age. Those who were always in a cohabiting relationship were less likely to exhibit structured parenting; no further significant difference from the always married group was detected.

The changing socio-economic environment models whether families experienced changes in income or educational qualifications from the baseline measurements. Once baseline socioeconomic indicators were included, there was no further association between family structure trajectories and educational qualifications at age 3 (Table 3B). Income at age 3 was however significantly associated with family structure trajectories (except for the cohabitees who married, and the single parents who re-partnered), indicating that groups lost income as family structure changed.

\section{Intermediate models}

Next, we considered variables that are specific to each health outcome, starting with the respiratory health models. Socio-economic background at 9 months was strongly linked to behavioural variables such as parental smoking and breastfeeding initiation (Table 3C). After control for this socio-economic variation, most family structure trajectories were still more likely to report parental smoking at age 3 and maternal smoking during pregnancy, and less likely to have initiated breastfeeding than the continuously married group, although there were exceptions. For example, the "always single parents" had a similar smoking profile at age 3 to the married group. Cohabitees who married, married parents who separated, and single parents who married, were similar in terms of smoking during pregnancy and breastfeeding initiation to the always married group. For the physical environment, after socio-economic markers were included, only the "always cohabiting" 
group was more likely to be living in a damp home than the married group, no other significant differences were detected.

In addition to a number of variables considered above, for overweight and obesity (Table 3D), we also consider regular eating patterns and child inactivity. Once strong variations in socioeconomic profiles were accounted for, few additional differences across family structure trajectories were noted. The "always single parent" group was less likely to report regular meal times than the always married group. The coupled parents who separated were less likely to report regularly having breakfast than the always married group. No differences across family trajectories were noted for screen time.

Finally, for the accidental injury models (Table 3E), the association between being a car passenger with family structure trajectories, after socio-economic antecedents were adjusted for, was mixed. Compared to the always married group, children living with always cohabiting parents and cohabiting parents who married were slightly more likely to use a car as passengers, while those living with always single parents and cohabitees who separated were less likely to use a car. Furthermore, once socio-economic antecedents are included, all family trajectories were less likely to include other siblings in their household than the always married group (except for married parents who separated and single parents who married, where there was no significant difference). Compared to the always married group, overcrowding was less common in three groups (always single parent, married and cohabiting parents who separate) but slightly more common for the always cohabiting and cohabiting parents who married. There were few differences across family trajectories for neighbourhood safety, except for the always cohabiting and always single groups 
who were more likely to report not living in a safe neighbourhood than the always married group. All trajectories reported more chaotic homes than the always married group, except for the singles who married, where there is no significant difference.

\section{Final models}

Tables 4 presents parameter estimates for all the blocks regressed against ever asthma and recent wheeze at age 5 . Most of the initial differences in asthma by family structure trajectories and by socio-economic baseline markers are attenuated by model variables (with the exception of the always single group, who are still more likely to report asthma). This indicates that we describe most of the potential mechanisms that might mediate the relationship between these variables and asthma: breastfeeding initiation, damp housing, and maternal malaise and attachment at 9 months of age. Similarly, after all variables are entered in the recent wheeze model, all family structure trajectories are no longer significantly different from the "always married" group, except again for the "always single parent" (slightly higher risk of wheeze) and the single to married group (slightly lower risk of wheeze). Malaise, maternal mental health at 3 years of age, and damp housing emerge as potential pathways.

Turning to overweight and obesity (Table 5), once all blocks are taken in account, family change trajectories are not associated with an increased risk of overweight or obesity at age 5, except for living with a cohabiting parent who separated, which increased the risk compared to those living with continuously married parents. Smoking during pregnancy, regular breakfast, screen time, and parental attachment appeared to be important underlying mechanisms. 
For accidental injury, the socio-economic antecedents were no longer associated with injury in the final models (Table 6). However, a number of family structure trajectories remained significantly associated to an increased risk of accidents, suggesting that for this outcome our models were probably not capturing all underlying mechanisms. The number of siblings in the home, agreeing with the statement "you can't hear yourself think", and maternal malaise at 9 months were associated with an increased risk of injury at age 5, suggesting that these variables as potential mediators. 


\section{Discussion}

Both cross sectional $[1,31]$ and longitudinal studies $[8,12,33]$ have shown that family structures are strongly intertwined with socio-economic background. Most previous work has focused on differentials in child well-being across family structures, in this paper we attempt to describe potential proximate pathways underscoring the interplay between family structure and its socioeconomic context on the one hand, and three different measures of early child physical health on the other. While remaining descriptive, this type of evidence allows better understanding of the relationship between the family context and child well-being, and can inform effective policies. We focus on early physical health as a neglected yet critical component of child well-being, and replicate models for three different types of health outcomes (respiratory health, excess weight, and accidental injuries), taking a holistic approach to "health" as well as providing robustness to our findings.

We showed that, first, when thinking about family structure and child well-being, we cannot consider marital status, trajectory stability and transitions separately: these components are distinctively important and appear to interplay to shape child health. Second, some of the pathways we highlight (particularly the outcome-specific ones, for example, not having regular eating patterns and long screen times for overweight; living in a damp house for respiratory health; or variables identifying the chaotic nature of the home for accidental injuries) show how the disadvantaged environments that children living in different family structure trajectories might impact their health. These risks are not evenly distributed: as shown in the intermediate models, 
they correlate with socio-economic background (rather than the family trajectory per se, with some exceptions).

Third, the intermediate models also suggest that certain pathways might matter more for different family trajectories. For example, the always cohabiting group appears to be particularly marked by poor housing: they are more likely to live in overcrowded, damp homes in neighbourhoods they do not feel safe in. This could be partly due to their more precarious housing tenure (40\% of this group does not own their home at wave 2 , versus $15 \%$ in the always married group). Indeed, qualitative research [72, 73] has shown that for young cohabitators, high marital expectations (including in terms of housing stability) may be precluding them from marrying. Another example of a trajectory-specific pathway is for the regularly eating breakfast: this variable predicted the risk of overweight in the final models, and the intermediate models suggest that it is in particular partnered households who experience a separation who are less likely to provide a regular breakfast to the cohort child. Parenting and especially routines such as regular meals have been shown to be affected by "shocks" such as parental separation and divorce [74], and our results suggest that, for this trajectory, parents' ability to maintain children's routine might potentially explain part of their increased risk of poor child health.

Finally, "family stress" variables emerged as an important potential pathway to understand differentials across all domains of early health and for most family structure trajectories. These variables are not often considered when dealing with childhood physical health, yet it is plausible that young children's main source of stress might come from their home environment, as measured, for example, by low levels of parental well-being. This result highlights the need to 
consider family well-being holistically when studying child well-being, including their physical health.

As in any secondary analyses of large datasets, there are some considerations to keep in mind when interpreting results. First, while we propose a conceptual model in which the direction of the association between variables, and the ordering of variables, is explicitated, our analyses are not causal and can only describe associations between variables, and suggest potential mechanisms through which these associations run.

Second, even though the Millennium Cohort Study is representative of children living in the UK, initial response rates and subsequent attrition result in a wealthier sample made up of less mobile households when compared to the general population. The results may therefore underestimate the gap between different family structures, as "lost" households are more likely to be unmarried and to experience family structure transitions, especially as changes in family structures often result in changes in residence. Survey weights, applied to all analyses, take account of sample attrition. Third, not all households answered all questions posed to them, resulting in cases with incomplete data. As incomplete data tends to relate to poorer, more disadvantaged households, we may be underestimating the true relationship between socio-economic variables and the proximate mechanisms studied. As detailed in the methodology section, we take a number of strategies to take account of this. Finally, parental report of child outcomes may introduce some bias. In particular, asthma and wheeze are difficult concepts to fully understand, and diagnosis of asthma among very young children is complicated. Parental reports of asthma and wheeze are therefore unlikely to be always accurate. Furthermore, certain pathway variables are difficult to 
operationalise in a survey setting, and may therefore not accurately measure the concept they were intended to approximate in the model. For example, in the Millennium Cohort Study, questions on children's diets were designed to tap into several dimensions of diet. However, only questions on eating regularly predicted BMI, while questions on the types of food eaten were not. Potentially, asking questions on whether children eat "mostly sugary foods in-between meals" may lead parents to give more socially acceptable answers. Similarly, questions on exercise attempted to captures both active and inactive behaviour. While questions on inactive behaviour (hours watching TV or playing videogames) did predict excess weight, questions on active behaviour (how often the child plays sports, whether the child walks to school, etc.) are harder to formulate and did not predict BMI. Reverse causation may also be an issue: parents of overweight or obese children may over-report physical activity, and under-report unhealthy dietary habits. Parents of overweight or obese children may also attempt to increase their child's activity levels, and improve their dietary habits. And potentially important pathways variables, such as parental supervision for the injury model, are difficult to operationalize without observational fieldwork.

Nonetheless, this study is one of few to explore the association between family structure trajectories and early physical health, as opposed to more commonly reported outcomes such as cognitive development or behaviour in older children. The early pre-school years, a critical developmental age, is often missing from the family structure and child well-being literature. Using a large, prospective, nationally representative study, we were able to distinguish between detailed longitudinal measures of family structure, showing that the use of simple or crosssectional variables to describe family structure disguises important differences between groups, even in early life. Our interdisciplinary conceptual model allowed us to include a number of 
spheres of a child's life, including psychosocial variables such as parental mental health; environmental variables such as housing quality; and health behaviours such as eating patterns and inactivity.

\section{Conclusion}

This study explored associations between family structure trajectories and three sets of child health outcomes, and described pathways through which family trajectories and their socio-economic context could operate to influence child health. Proximal variables through which the more distal variables of socio-economic background and family structure varied as expected by health

outcome; "family stress" came across as a potentially important pathway across all health outcomes. With few exceptions, once all model variables were accounted for, there were no significant differences between different family structure trajectories in early child physical health. 


\section{Acknowledgments}

Thanks go to the two anonymous peer-reviewers for helpful comments on this article. We would like to thank the Millennium Cohort Study families for their time and cooperation, as well as the Millennium Cohort Study team at the Institute of Education, UCL. The Millennium Cohort Study is funded by the Economic and Social Research Council (ESRC). This work was partly funded through an ESRC and Medical Research Council Research Interdisciplinary Studentship and an ESRC Postdoctoral Fellowship to Lidia Panico.

\section{Appendix A. Supplementary data}

Supplementary data to this article can be found online at https://doi.org/10.1016/j.socscimed.2019.05.006 


\section{Figures}

Figure 1: Conceptual model

\section{Tables}

Table 1: Typologies of family structure trajectories, birth to age 5.

Table 2: Proportion children reporting health outcome at age 5, by family structure trajectory.

Table 3: Relative Risk Ratios for multinomial regression model of family structure trajectories on block 1 variables.

Table 4: Odds Ratios from a logistic regression, all blocks on ever asthma and wheeze at 5 years of age.

Table 5: Odds Ratios from a logistic regression, all blocks on being overweight/obese at 5 years of age.

Table 6: Odds Ratios from a logistic regression, all blocks on injury requiring a medical visit.

(see separate files for figures and tables) 


\section{Bibliography}

1. Amato, P.R., The Impact of Family Formation Change on the Cognitive, Social, and Emotional Well-Being of the Next Generation. The Future of Children, 2005. 15(2): p. 75-92.

2. Osborne, C. and S. McLanahan, Partnership instability and child wellbeing. Journal of Marriage and Family, 2007. 69(4): p. 1065-1083.

3. Magnuson, K. and L.M. Berger, Family structure states and transitions: associations with children's wellbeing during middle childhood. Journal of Marriage and Family, 2009. 71(3): p. 575-591.

4. Bzostek, S.H. and L.M. Berger, Family Structure Experiences and Child Socioemotional Development During the First Nine Years of Life: Examining Heterogeneity by Family Structure at Birth. Demography, 2017. 54(2): p. 513540.

5. Lacey, R.E., et al., Parental separation and adult psychological distress: an investigation of material and relational mechanisms. BMC public health, 2014. 14(1): p. 272.

6. McLanahan, S., L. Tach, and D. Schneider, The Causal Effects of Father Absence. Annual Review of Sociology, 2013. 39(1): p. 399-427.

7. Kiernan, K. and F. Mensah, Partnership trajectories, parent and child well-being. Children of the 21st century: the first five years, 2010. 2: p. 77.

8. Panico, L., et al., Changes in family structure in early childhood in the Millennium Cohort Study. Population Trends, 2010. 142(1): p. 78-92.

9. Amato, P.R. and C.J. Anthony, Estimating the effects of parental divorce and death with fixed effects models. Journal of Marriage and Family, 2014. 76(2): p. 370-386.

10. McLanahan, S., L. Tach, and D. Schneider, The causal effects of father absence. Annual Review of Sociology, 2013. 39: p. 399-427.

11. Magnuson, K. and L.M. Berger, Family structure states and transitions: associations with children's well - being during middle childhood. Journal of Marriage and Family, 2009. 71(3): p. 575-591.

12. Kiernan, K. and F.K. Mensah, Poverty, family resources and children's early educational attainment: the mediating role of parenting. British Educational Research Journal, 2011. 37(2): p. 317-336.

13. McLanahan, S., Diverging destinies: How children are faring under the second demographic transition. Demography, 2004. 41(4): p. 607-627.

14. Cherlin, A.J., Demographic trends in the United States: A review of research in the 2000s. Journal of Marriage and Family, 2010. 72(3): p. 403-419.

15. Isen, A. and B. Stevenson, Women's education and family behavior: Trends in marriage, divorce and fertility, 2010, National Bureau of Economic Research.

16. Sigle-Rushton, W., J. Hobcraft, and K. Kiernan, Parental divorce and subsequent disadvantage: A cross-cohort comparison. Demography, 2005. 42(3): p. 427-446.

17. Cavanagh, S.E. and A.C. Huston, The timing of family instability and children's social development. Journal of Marriage and Family, 2008. 70(5): p. 1258-1270.

18. Bzostek, S.H. and A.N. Beck, Familial instability and young children's physical health. Social Science \& Medicine, 2011. 73(2): p. 282-292. 
19. Harknett, K., Why are children with married parents healthier? The case of pediatric asthma. Population Research and Policy Review, 2009. 28(3): p. 347365.

20. Schmeer, K.K., The child health disadvantage of parental cohabitation. Journal of Marriage and Family, 2011. 73(1): p. 181-193.

21. Sweeney, M.M., Remarriage and stepfamilies: Strategic sites for family scholarship in the 21st century. Journal of Marriage and Family, 2010. 72(3): p. 667-684.

22. McLanahan, S. and C. Percheski, Family structure and the reproduction of inequalities. Annu. Rev. Sociol, 2008. 34: p. 257-276.

23. Perales, F., M. O'Flaherty, and J. Baxter, Early Life Course Family Structure and Children's Socio-Emotional and Behavioural Functioning: A View from Australia. Child Indicators Research, 2016. 9(4): p. 1003-1028.

24. Gähler, M. and A. Garriga, Has the association between parental divorce and young adults' psychological problems changed over time? Evidence from Sweden, 1968-2000. Journal of Family Issues, 2013. 34(6): p. 784-808.

25. Härkönen, J. and J. Dronkers, Stability and change in the educational gradient of divorce. A comparison of seventeen countries. European Sociological Review, 2006. 22(5): p. 501-517.

26. Kiernan, K. and K.E. Pickett, Marital status disparities in maternal smoking during pregnancy, breastfeeding and maternal depression. Social Science and Medicine, 2006. 63(2): p. 335-346.

27. Pearce, A., H. Lewis, and C. Law, The role of poverty in explaining health variations in 7-year-old children from different family structures: findings from the UK Millennium Cohort Study. Journal of epidemiology and community health, 2013. 67(2): p. 181-189.

28. Mariani, E., B. Özcan, and A. Goisis, Family Trajectories and Well-being of Children Born to Lone Mothers in the UK. European Journal of Population, 2017. 33(2): p. 185-215.

29. McMunn, A.M., et al., Children's emotional and behavioural well-being and the family environment: findings from the Health Survey for England. Social Science and Medicine, 2001. 53(4): p. 423-440.

30. Kiernan, K. and F.K. Mensah, Poverty, maternal depression, family status and children's cognitive and behavioural development in early childhood: A longitudinal study. Journal of Social Policy, 2009. 38(04): p. 569-588.

31. Schoon, I., et al., Family hardship and children's development: the early years. longitudinal and life Course studies, 2010. 1(3): p. 209-222.

32. Berrington, A., The changing demography of lone parenthood in the UK, in Working Paper 48, E.C.f.P. Change;, Editor 2014: Southampton, UK.

33. Leturcq, M. and L. Panico, The long-term effect of parental separation on childhood financial poverty and multidimensional deprivation: a lifecourse approach, in Documents de Travail, INED, Editor 2016: Paris, France.

34. Blane, D., et al., Social-biological transitions: how does the social become biological? longitudinal and life Course studies, 2013. 4(2): p. 136-146.

35. Blau, D.M., The effect of income on child development. Review of Economics and Statistics, 1999. 81(2): p. 261-276. 
36. Becker, G.S., A Treatise on the Family1981: Harvard university press.

37. Bartley, M., Health inequality: an introduction to concepts, theories and methods2016: John Wiley \& Sons.

38. Stringhini, S., et al., Association of socioeconomic position with health behaviors and mortality. Jama, 2010. 303(12): p. 1159-1166.

39. Masarik, A.S. and R.D. Conger, Stress and child development: a review of the Family Stress Model. Current Opinion in Psychology, 2017. 13: p. 85-90.

40. Conger, R.D., et al., Economic stress, coercive family process, and developmental problems of adolescents. Child development, 1994. 65(2): p. 541-561.

41. Musick, K. and A. Meier, Are both parents always better than one? Parental conflict and young adult well-being. Social science research, 2010. 39(5): p. 814830.

42. Mensah, F.K. and K.E. Kiernan, Parents' mental health and children's cognitive and social development. Social psychiatry and psychiatric epidemiology, 2010. 45(11): p. 1023-1035.

43. Linver, M.R., J. Brooks-Gunn, and D.E. Kohen, Family processes as pathways from income to young children's development. Developmental psychology, 2002. 38(5): p. 719.

44. Thoits, P.A., Stress and health major findings and policy implications. Journal of health and social behavior, 2010. 51(1 suppl): p. S41-S53.

45. Chen, E., et al., Socioeconomic status and inflammatory processes in childhood asthma: the role of psychological stress. Journal of Allergy and Clinical Immunology, 2006. 117(5): p. 1014-1020.

46. Chen, E., et al., Socioeconomic status, stress, and immune markers in adolescents with asthma. Psychosomatic Medicine, 2003. 65(6): p. 984-992.

47. Gump, B.B., et al., Blood lead $(\mathrm{Pb})$ levels: a potential environmental mechanism explaining the relation between socioeconomic status and cardiovascular reactivity in children. Health Psychology, 2007. 26(3): p. 296.

48. McEwen, B.S., Protective and damaging effects of stress mediators. New England journal of medicine, 1998. 338(3): p. 171-179.

49. Lohman, B.J. and P.A. Jarvis, Adolescent stressors, coping strategies, and psychological health studied in the family context. Journal of youth and adolescence, 2000. 29(1): p. 15-43.

50. McEwen, B.S., Allostasis and allostatic load: implications for neuropsychopharmacology. Neuropsychopharmacology, 2000. 22(2): p. 108-124.

51. Bronfenbrenner, U., Ecology of the family as a context for human development: Research perspectives. Developmental psychology, 1986. 22(6): p. 723.

52. Wright, R.J., M. Rodriguez, and S. Cohen, Review of psychosocial stress and asthma: an integrated biopsychosocial approach. Thorax, 1998. 53(12): p. 10661074.

53. Roberts, I., C. DiGuiseppi, and H. Ward, Childhood injuries: extent of the problem, epidemiological trends, and costs. Injury prevention, 1998. 4(suppl 1): p. S10-S16.

54. Roberts, I. and B. Pless, Social policy as a cause of childhood accidents: the children of lone mothers. BMJ: British Medical Journal, 1995. 311(7010): p. 925. 
55. Hendrickson, S.G., Maternal worries, home safety behaviors, and perceived difficulties. Journal of nursing scholarship, 2008. 40(2): p. 137-143.

56. Brussoni, M., E. Towner, and M. Hayes, Evidence into practice: combining the art and science of injury prevention. Injury prevention, 2006. 12(6): p. 373-377.

57. Dex, S. and H. Joshi, Children of the 21st century: from birth to nine months2005: Policy Press.

58. Hansen, K., Millennium Cohort Study first, second, third and fourth surveys: a guide to the datasets 6th edn. London: Centre for Longitudinal Studies, University of London, 2012.

59. Cole, T.J., et al., Body mass index cut offs to define thinness in children and adolescents: international survey. Bmj, 2007. 335(7612): p. 194.

60. Cole, T.J., J.V. Freeman, and M.A. Preece, British 1990 growth reference centiles for weight, height, body mass index and head circumference fitted by maximum penalized likelihood. Statistics in medicine, 1998. 17(4): p. 407-429.

61. Rodgers, B., et al., Validity of the malaise inventory in general population samples. Soc Psychiatry Psychiatr Epidemiol, 1999. 34.

62. Kessler, R.C., et al., Short screening scales to monitor population prevalences and trends in non-specific psychological distress. Psychological medicine, 2002. 32(06): p. 959-976.

63. Rust, J. and S. Golombok, The GRISS: a psychometric instrument for the assessment of sexual dysfunction. Archives of Sexual Behavior, 1986. 15(2): p. 157-165.

64. Condon, J.T. and C.J. Corkindale, The assessment of parent-to-infant attachment: development of a self-report questionnaire instrument. Journal of Reproductive and Infant Psychology, 1998. 16(1): p. 57-76.

65. Pianta, R., Rating scales for parent-child interaction in preschoolers. University of Virginia, 1994.

66. Waters, E. and K.E. Deane, Defining and assessing individual differences in attachment relationships: Q-methodology and the organization of behavior in infancy and early childhood. Monographs of the society for research in child development, 1985: p. 41-65.

67. Berrington, A., et al., A graphical chain model for reciprocal relationships between women's gender role attitudes and labour force participation. Journal of the Royal Statistical Society: Series A (Statistics in Society), 2008. 171(1): p. 89108.

68. STATA CORP, STATA Software Release 14, 2015, StataCorp LP: College Station, TX.

69. White, I.R., P. Royston, and A.M. Wood, Multiple imputation using chained equations: issues and guidance for practice. Statistics in medicine, 2011. 30(4): p. 377-399.

70. Allison, P.D., Missing data: Quantitative applications in the social sciences. British Journal of Mathematical and Statistical Psychology, 2002. 55(1): p. 193196.

71. Rubin, D.B., Multiple imputation for nonresponse in surveys. Vol. 81. 2004: John Wiley \& Sons. 
72. Gibson - Davis, C.M., K. Edin, and S. McLanahan, High hopes but even higher expectations: The retreat from marriage among low -income couples. Journal of Marriage and Family, 2005. 67(5): p. 1301-1312.

73. Edin, K., What do low-income single mothers say about marriage? Social Problems, 2000. 47(1): p. 112-133.

74. Leturcq, M. and L. Panico, The long-term effect of parental separation on childhood financial poverty and multidimensional deprivation: a lifecourse approach, in Documents de travail Ined, Editor 2016: Paris. 


\section{Tables}

\begin{tabular}{l|c|c}
\hline \multicolumn{3}{c}{ Table 1: Typologies of family structure trajectories, birth to age 5 } \\
\hline & $\begin{array}{c}\text { \% (imputed } \\
\text { and weighted) }\end{array}$ & $\begin{array}{l}\text { Unweighted sample } \\
\text { size, before imputations }\end{array}$ \\
\hline No changes & & \\
$\quad$ Always married & 56.0 & 7148 \\
Always cohabiting & 11.1 & 1398 \\
Always single parent & 5.9 & 908 \\
\hline Total & $\mathbf{7 3 . 0}$ & $\mathbf{9 4 5 4}$ \\
& & \\
One transition & 6.5 & 788 \\
$\quad$ Cohabiting to married & 4.4 & 556 \\
$\quad$ Married to single parent & 3.8 & 474 \\
Cohabiting to single parent & 3.4 & 506 \\
Single parent to cohabiting & 1.3 & 240 \\
$\quad$ Single parent to married & $\mathbf{1 9 . 4}$ & $\mathbf{2 5 6 4}$ \\
Total & 7.6 & 990 \\
More than one transition & & 14678 \\
Total imputed sample size & & 13008 \\
Total not imputed sample & & \\
\hline
\end{tabular}




\begin{tabular}{|c|c|c|c|c|}
\hline & $\begin{array}{l}\text { Recent } \\
\text { wheeze }\end{array}$ & $\begin{array}{l}\text { Ever } \\
\text { asthma }\end{array}$ & $\begin{array}{l}\text { Overweight } \\
\text { or obese }\end{array}$ & $\begin{array}{l}\text { At least } 1 \\
\text { accident }\end{array}$ \\
\hline Always married & 14.2 & 11.9 & 21.5 & 25.4 \\
\hline Always cohabiting & 15.4 & 14.6 & 23.2 & 29.5 \\
\hline Always single parent & 25.3 & 22.7 & 28.5 & 34.0 \\
\hline Cohabiting to married & 14.5 & 15.4 & 23.2 & 27.8 \\
\hline Married to single parent & 14.2 & 17.7 & 18.5 & 26.7 \\
\hline Cohabiting to single parent & 21.4 & 20.0 & 29.3 & 29.2 \\
\hline Single parent to cohabiting & 19.8 & 20.6 & 25.6 & 33.9 \\
\hline Single parent to married & 11.7 & 12.9 & 23.1 & 28.3 \\
\hline More than 1 transition & 19.1 & 17.2 & 22.2 & 34.6 \\
\hline Total sample size $(\mathbf{N})$ & 14678 & 14678 & 14678 & 14678 \\
\hline p-value & $<0.0001$ & $<0.0001$ & 0.002 & $<0.0001$ \\
\hline
\end{tabular}


Table 3: Relative Risk Ratios for multinomial regression model of family structure trajectories on block 1 variables.

$\frac{\text { Comparison category is the "always married" group }}{\text { Always }}$

\section{Always}

single

$0.54 * *$
$1.01 * *$
$0.89 * *$
$0.81 * *$
$0.99 *$

$0.51 * *$

$1.01 * *$

$0.75 * *$

$0.27 * *$

$0.87 * *$

14678

\begin{tabular}{|c|c|c|}
\hline $\begin{array}{l}\text { Cohat } \\
\text { who n }\end{array}$ & $\begin{array}{l}\text { Married } \\
\text { to single }\end{array}$ & $\begin{array}{l}\text { Cohabiting } \\
\text { to single }\end{array}$ \\
\hline
\end{tabular}

$0.64 * * \quad 0.91$

0.91

$0.52 * *$

$0.42 * *$

$1.01 * *$

$0.59 * *$

$0.52 * *$

$1.01 * *$

$0.92 *$

$1.01 * *$

$0.77 * *$

$1.01 * *$

$1.01 *$

$0.40 * *$

$0.28 * *$

$0.58 * *$

$0.74 * *$

$0.84 * *$

0.94

0.99

$0.98 *$

$0.90 * *$

$0.64 *$

$0.93 * *$

$0.44 * *$

0.97 * 
Table 4: Odds Ratios from a logistic regression, all blocks on ever asthma and wheeze at 5 years of age.

Comparison category is "always married"

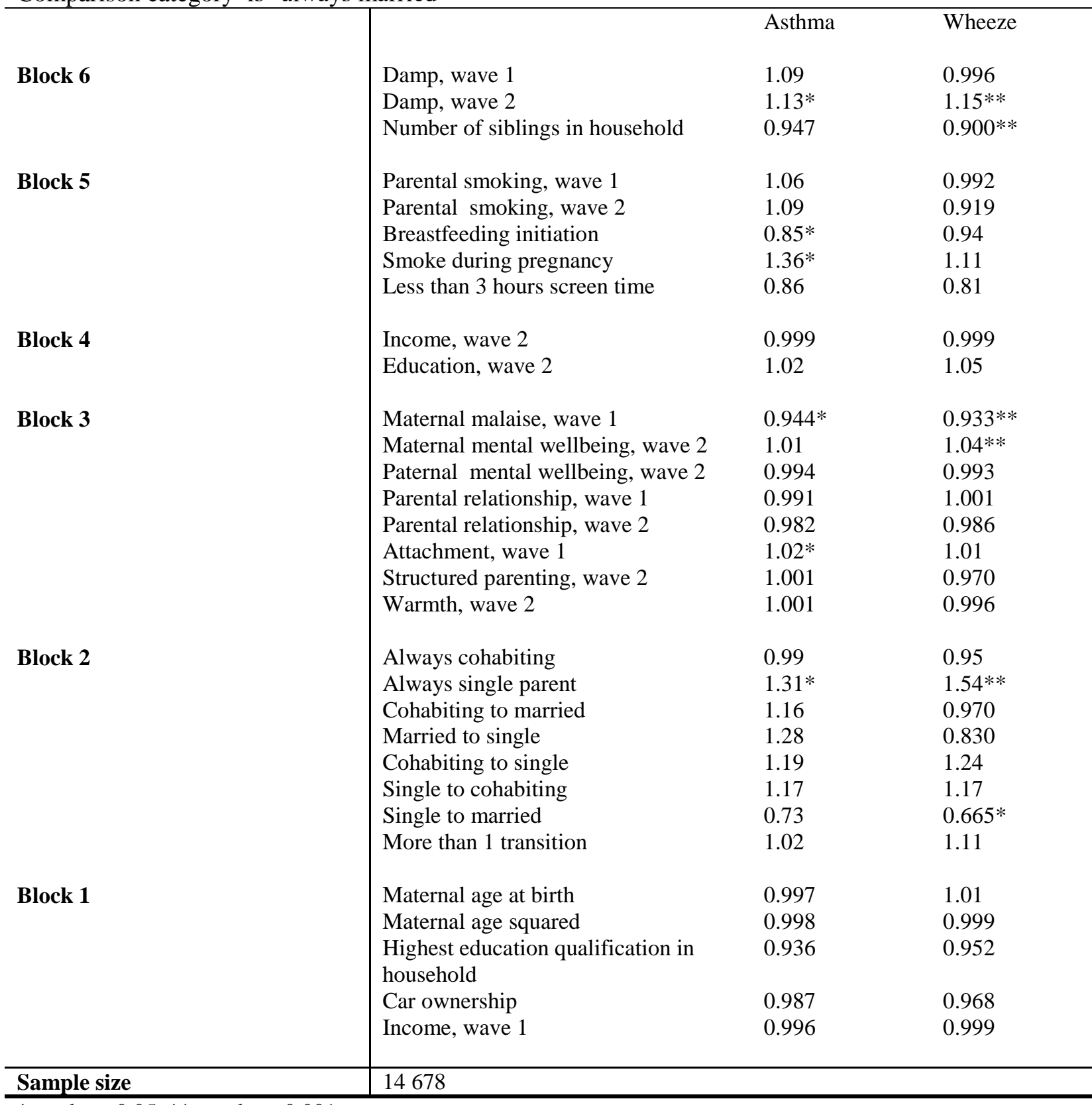


Table 5: Odds Ratios from a logistic regression, all blocks on being overweight/obese at 5 years of age. Comparison category is "always married"

Block 5

Smoking during pregnancy

$1.18^{*}$

Parental smoking. wave 1

1.11

Parental smoking, wave 2

0.901

Breastfeeding initiation

1.16*

Eat meals at regular times

0.820

Regular breakfast

$0.707 * *$

Less than 3 hours screen time

$0.870^{*}$

Block 4

Income, wave 2

0.999

Education, wave 2

Block 3

Maternal malaise, wave 1

0.975

Maternal mental wellbeing, wave 2

0.989

Paternal mental wellbeing, wave 2

0.992

Parental relationship, wave 1

0.977

Parental relationship, wave 2

0.983

Attachment, wave 1

$1.06^{*}$

Structured parenting, wave 2

0.952

Warmth, wave 2

1.01

Block 2

Always cohabiting

1.09

Always single parent

$1.43^{*}$

Cohabiting to married

1.27

Married to single

0.977

Cohabiting to single

$1.61 *$

Single to cohabiting

Single to married

1.14

More than 1 transition

0.921

Block 1

Maternal age at birth

0.998

Maternal age squared

0.938

Highest education qualification in household

0.938

Car ownership

1.15

Income, wave 1

0.995

\section{Sample size}

14678

$*$ p-value $<0.05, * *$ p-value $<0.001$ 
Table 6: Odds Ratios from a logistic regression, all blocks on injury requiring a medical visit. Comparison category is "always married"0

Block 6

Block 5

Block 4

Block 3

Block 2

Block 1
Number siblings in the household

$1.19 *$

Overcrowding

0.735

Safety of neighborhood

0.965

Atmosphere in home

$1.20 *$

Use car as passenger

Income, wave 2

0.999

Education, wave 2

0.977

Maternal malaise, wave 1

$0.935^{*}$

Maternal mental wellbeing, wave 2

1.001

Paternal mental wellbeing, wave 2

0.977

Parental relationship, wave 1

1004

Parental relationship, wave 2

1.005

Attachment, wave 1

1.001

Structured parenting, wave 2

0.996

Warmth, wave 2

1.001

Always cohabiting

$1.13^{*}$

Always single parent

$1.39 *$

Cohabiting to married

1.06

Married to single

0.834

Cohabiting to single

1.22

Single to cohabiting

$1.26^{*}$

Single to married

0.806

More than 1 transition

Maternal age at birth

0.969

Maternal age squared

1.002

Highest education qualification in household

1.06

Car ownership

1.14

Income, wave 1 